\title{
THERMOPHYSICAL AND MECHANICAL PROPERTIES OF BISPHENOL A EPOXY RESIN FILLED WITH MULTIWALLED CARBON NANOTUBES
}

\author{
A. Borisova, T. Glaskova-Kuzmina, and A. Aniskevich \\ Institute of Polymer Mechanics, University of Latvia, 23 Aizkraukles Street, LV-1006 Riga, Latvia \\ E-mail: Anna.Borisova@pmi.lu.lv
}

Received 22 May 2015; revised 11 June 2015; accepted 29 September 2015

\begin{abstract}
Dilatometric tests, thermal mechanical analysis (TMA), quasistatic tensile tests, hydrostatic weighting, and scanning electron microscopy (SEM) were performed on the multiwalled carbon nanotube (MWCNT)/epoxy nanocomposite (NC) with different filler content ( $c=0-3.8 \% \mathrm{wt}$.) in order to determine the influence of MWCNT content on the thermophysical and mechanical properties of NC. The experimental results show the physical properties versus the nanofiller content and the existence of the optimal MWCNT content (1\% wt.) in epoxy resin that maximally improves the thermophysical properties of NC in comparison with unfilled epoxy. Thus, NC with $1 \%$ wt. filler content shows the maximal decrease of thermal expansion coefficient by $68 \%$, the maximal increase of glass transition temperature and tensile strength by $23^{\circ} \mathrm{C}$ and $18 \%$, respectively. Comparing the results it can be seen that after exceeding the defined optimal filler content over $1 \%$ wt. the investigated properties get worse. The correlation between the investigated mechanical and thermophysical properties is estimated and reported.
\end{abstract}

Keywords: carbon nanotubes, epoxy resin, nanocomposite

PACS: 61.48.De

\section{Introduction}

Over the last decade, nano-reinforced polymer matrix composites have attracted much of attention due to their potentially superior mechanical and physical properties. One of the important materials often used in engineering, aerospace and other industries is epoxy resin which has highly competitive physical properties [1]. The incorporation of nanofillers such as nanoclays [2], silica nanoparticles [3], graphene nanoparticles [it etc. into a polymer matrix, offers the ability to modify its mechanical properties such as to fit the design requirements. Carbon nanotubes (CNTs) are amongst the most promising nano-fillers due to their unique mechanical, thermal and electrical characteristics [5] and have therefore been the subject of extensive research over the last few years by different methods [1-10]. Issues such as the effect of CNTs volume fraction, the degree of dispersion and filler/ epoxy adhesion on the mechanical [9-11], thermomechanical [10-11] and electrical properties [11, 12] of CNT-reinforced polymers have been addressed by a number of researchers, and a brief summary of the main findings is given below.
The addition of CNTs can improve important thermomechanical properties of the polymer composite. One of the most crucial characteristics of epoxy resin is glass transition temperature $T_{\mathrm{g}}$. It is dependent on the polymer microstructure and curing process. Epoxies with higher $T_{\mathrm{g}}$ have the increased heat resistance and therefore deliver higher tensile properties at increased temperatures. The presence of CNTs can reduce the polymer free volume and can impact on the structure of cured epoxy by restricting the polymeric interaction during the cure reaction, by influencing the polymer chain alignment, and by reducing the mobility of polymer macromolecules near the interface between nanoparticles and epoxy [11, 13, thus affecting the $T_{\mathrm{g}}$ of NC.

Another important thermophysical characteristic that can occur with changing $T_{\mathrm{g}}$ is the coefficient of thermal expansion (CTE). It is used to determine the failure by thermal stresses that may occur when a solid body is subjected to temperature variations. CNTs have low CTE due to their high bond energy and rigidity [13]. It is therefore expected that their presence due to reduction of a free volume of the polymer network and reduction of thermally 
induced movements within the polymer matrix will decrease the CTE of NC.

Since the presence of a nanofiller determines the microstructure of the composite, it is apparent that it will also influence its mechanical properties. The extremely large interphase between nano-fillers and polymer and high aspect ratio [14, 15, offer the opportunity for a much greater improvement of the mechanical performance of nano-reinforced polymers when compared to micro-reinforced ones 16]. A number of theoretical models [5, 16] predict a significant increase in the elastic modulus of nano-reinforced composites which is attributed to the impressively high elastic modulus of CNTs that can reach values up to $1 \mathrm{TPa}$ [5]. In reality, however, the achieved mechanical properties are far behind the idealized theoretical ones due to a number of factors (e. g. homogeneity of the composite, CNT aspect ratio, particle loading and size, test and manufacturing methods) which are not taken into consideration in the theoretical models but influence significantly the mechanical properties of NCs [5, 17]. Well dispersed CNTs should enhance the operation of epoxy resin, but at high nanofiller percentages (more than $0.5-1.0 \%$ wt.) due to excess surface energy the nanofiller causes the appearance of agglomerates and decreases improvement of thermophysical and mechanical properties of the material [11, 18, 19]. However, non-uniform dispersion of the filler particulates within the matrix has been identified as one of the key factors for deficient improvements of the physical properties of NC [20]. High loading of nanoparticles that usually can be compared with the statistical percolation threshold using the percolation theory [14] affects the viscosity and homogeneity of NC. Lack of interfacial adhesion [12] and development of the percolative network of nanoparticles are other factors that bear heavily on the material physical properties of the composite [14, 15]. A number of researchers have developed methods for the estimation $[7,8,12-$ $18,21,22$ and improvement of the dispersion degree, however, the optimal filler content corresponding to the material property under investigation is still experimentally determined in most cases. It is complicated to investigate the dispersion of the nanometer scale filler directly and to predict how the real dispersion will affect the properties of different NCs. The experimental results obtained in this work provided a comparable estimation of the influence of MWCNT content on the NC mechanical and thermophysical properties.

In view of numerous factors that influence the microstructure of CNT-filled polymer, reliable determination of its mechanical and thermal properties is really possible only through experiments. Thus, the objective of the current work is to estimate the correlation between the thermophysical and mechanical properties of the MWCNT/epoxy system in dependence on various loading content. A number of similar studies [ [ , 15] have been done. In this work the correlation between the investigated properties is outlined in order to obtain multifunctional characteristics of the material and increase the applicability. The latter is of great importance since the applicability of such composite systems in structural and engineering constructions of boats, aircrafts, automobiles, sport equipment and other commercial sectors depends on the combination of their thermal and mechanical properties.

\section{Experiment}

\subsection{Materials and specimen preparation}

Bisphenol A epoxy resin LH 289 and curing agent H 289 (mixing ratio 100:33 by weight), as well as epoxy resin masterbatch with 5\% wt. multiwall CNT were provided by Havel Composites (Czech Republic). Masterbatch with the previously dispersed CNT was mixed by the providing company. This type of neat epoxy resin has low viscosity, good stability to chemicals and high temperatures [23]. NC specimens were produced at different filler content $(0,0.2,0.5,1.0,1.9$, and $3.8 \%$ wt.) by mixing epoxy resin with masterbatch in necessary proportions.

According to provider's data the mean length of CNT in masterbatch was $0.2-5.0 \mu \mathrm{m}$, the outer diameter was $10-50 \mathrm{~nm}$, and the average aspect ratio was 90 . The critical percolation threshold for the MWCNTs was calculated [14] using the formula $\Phi=0.5 \cdot \alpha^{-1}$ where the aspect ratio is equal to $\alpha=L / D(L$ and $D$ are the CNT averaged length and diameter, respectively). According to the averaged values and these calculations the critical statistical percolation threshold for the MWCNTs is app. $0.8 \%$ wt. Filler contents were chosen according to the percolation threshold value $0,0.2,0.5,1.0,1.9$, and $3.8 \% \mathrm{wt}$. where two were near the percolation threshold, two well above and one well below it. NC specimens were produced by mixing a certain quantity of neat epoxy resin with masterbatch in the calculated proportions by weight. After the addition of the curing agent the maximal filler content was $3.8 \%$ wt.

First of all, the high viscosity of masterbatch because of high MWCNT addition and low storage temperature was reduced by increasing temperature from 8 till $20^{\circ} \mathrm{C}$. Secondly, after $1 \mathrm{~h}$ epoxy resin and masterbatch were manually and intensively mixed 
for 5 minutes. Then the necessary amount of a hardener was added, and all mixture was degasified for 10 minutes at room temperature. The silicon moulds were filled with mixed epoxy resin and cured for 22 hours at $15{ }^{\circ} \mathrm{C}$ in a heat chamber, and for 2 hours at $50^{\circ} \mathrm{C}$. Then for removing of technological stresses the specimens were post cured out of moulds for 24 hours at $60^{\circ} \mathrm{C}$. At the end all the NC specimens were polished for getting a flat surface and to minimize the influence of surface defects on the properties investigated during the experimental testing. The final dimensions of the samples were $150 \times 10 \times 2 \mathrm{~mm}$. All samples were desorbed in desiccators with silica gel for 2 months at room temperature (RT) and $17 \%$ of the relative humidity $(\mathrm{RH})$ of atmosphere before the experiments in order to guarantee the same conditions of testing.

\subsection{Measurements}

Measurement of the density of NC samples was carried out using analytical scales Mettler Toledo XS 205DU at the hydrostatic weighting regime in ethanol (density at $18{ }^{\circ} \mathrm{C} 0.791 \mathrm{~g} / \mathrm{cm}^{3}$ ) which does not influence resin. For each concentration of MWCNTs five NC samples were used. The features of thermal expansion and glass transition temperature of the NC specimens have been studied in two cycles of dilatometric analysis without external load. Thermophysical investigations were performed by a dilatometer UIP-70M using small specimens $(6 \times 6 \times 2 \mathrm{~mm})$ that were cut from dogbone specimens. They were heated in a temperature range from 20 to $100{ }^{\circ} \mathrm{C}$ at a heating rate of $2{ }^{\circ} \mathrm{C} / \mathrm{min}$ with subsequent natural cooling. Analyzing the obtained dilatometric curves the glass transition temperature $T_{\mathrm{g}}$ and the linear coefficient of thermal expansion (CTE) of NC were determined. Quasistatic tensile tests were performed using a universal testing machine Zwick 2.5 in a uniaxial tension regime at the constant traverse speed $5 \mathrm{~mm} / \mathrm{min}$ up to specimen failure. The tensile strength, strain at break, and tangential elastic modulus of NCs were determined from tensile stress-strain curves. Mechanical measurements were performed at $19^{\circ} \mathrm{C}$ temperature. For the most optimal filler content scanning electron microscopy (SEM) analysis by Zeiss EVO 50 (with output strain $20 \mathrm{kV}$ and current $100 \mathrm{pA}$ ) of the specimens' fracture surface at the vacuum level $10^{-7} \mathrm{~atm}$ and optimal voltage 2.3-2.5 A was performed. The fracture surface was previously covered with a thin $(10-20 \mathrm{~nm})$ electroconductive layer of platinum and palladium melt in the ratio 1:1 using a plasma discharge chamber with a low vacuum. Images were analyzed using the software SmartSEM user interface in order to investigate the structure of NC.

\section{Results and discussion}

\subsection{Morphology of fracture surface}

A scanning electron microscope was used to observe fracture surface morphology and MWCNT distribution within epoxy resin. The fracture surface shows a typical brittle failure of NC between the MWCNT and epoxy matrix (Fig. 1(a)). The surface is rough and non-homogeneous. The material is fractured in various planes that indicate strong MWCNT/epoxy resin adhesion. Such phenomenon is explained by Srivastava's [20] theoretical statement that the CNT network can block crack expansion, consequently with the increase of loading, cracks form in the weak CNTs network area.

Distribution of MWCNT is visible on (Fig. 1(b), (c). Where micro-agglomerates are observed, it indicates that in the nanolevel MWCNT are not perfectly distributed within the epoxy matrix, but in the microlevel (Fig. 1(c)) they have good dispersion. In general, the pinning of cracks by MWCNT filler can be observed.

Magnifying the observed surface by 560 times a polymer structure is clearly visible, and reaching a magnification of 20000 times CNT agglomerates can be seen (Fig. 1 (b), (c)). When the magnification reaches 132000 , it is possible to determine the geometrical parameters of a single nanotube or its visible part, the length of which is approximately $200-400 \mathrm{~nm}$ and the diameter is $30-50 \mathrm{~nm}$ (Fig. 1(d)). The maximal magnification allowed making the statement that the explored structure is indeed CNT. At reduced magnification CNT aggregates are observed in multiple locations.

\subsection{Density measurements}

Dependence of the NC density on the filler content was obtained by hydrostatical weighting. The densities of the unfilled epoxy-hardener mixture and those of the NCs with different filler content were measured following the procedure described in Section 2.2, whereas the density of CNT was taken from the manufacturer's datasheet $\left(\rho_{\mathrm{CNT}}=1.4 \mathrm{~g} / \mathrm{cm}^{3}\right)[23$. In order to estimate theoretical values the density of NCs was also calculated by employing the rule of mixtures:

$$
\rho_{\mathrm{c}}=\left(1-\frac{c_{\mathrm{CNT}}}{100}\right) \cdot \rho_{\mathrm{ep}}+\frac{c_{\mathrm{CNT}}}{100} \cdot \rho_{\mathrm{CNT}},
$$

where $\rho_{\mathrm{c}}, \rho_{\mathrm{ep}}$ and $\rho_{\mathrm{CNT}}$ are the density of the composite, epoxy resin and $\mathrm{CNTs}$, respectively, and $c_{\mathrm{CNT}}$ is the relative CNTs mass content in the composite. The density of epoxy resin and hardener mixture $\rho_{\mathrm{ep}}$ was $1.140 \pm 0.004 \mathrm{~g} / \mathrm{cm}^{3}$ (data from the datasheet). 

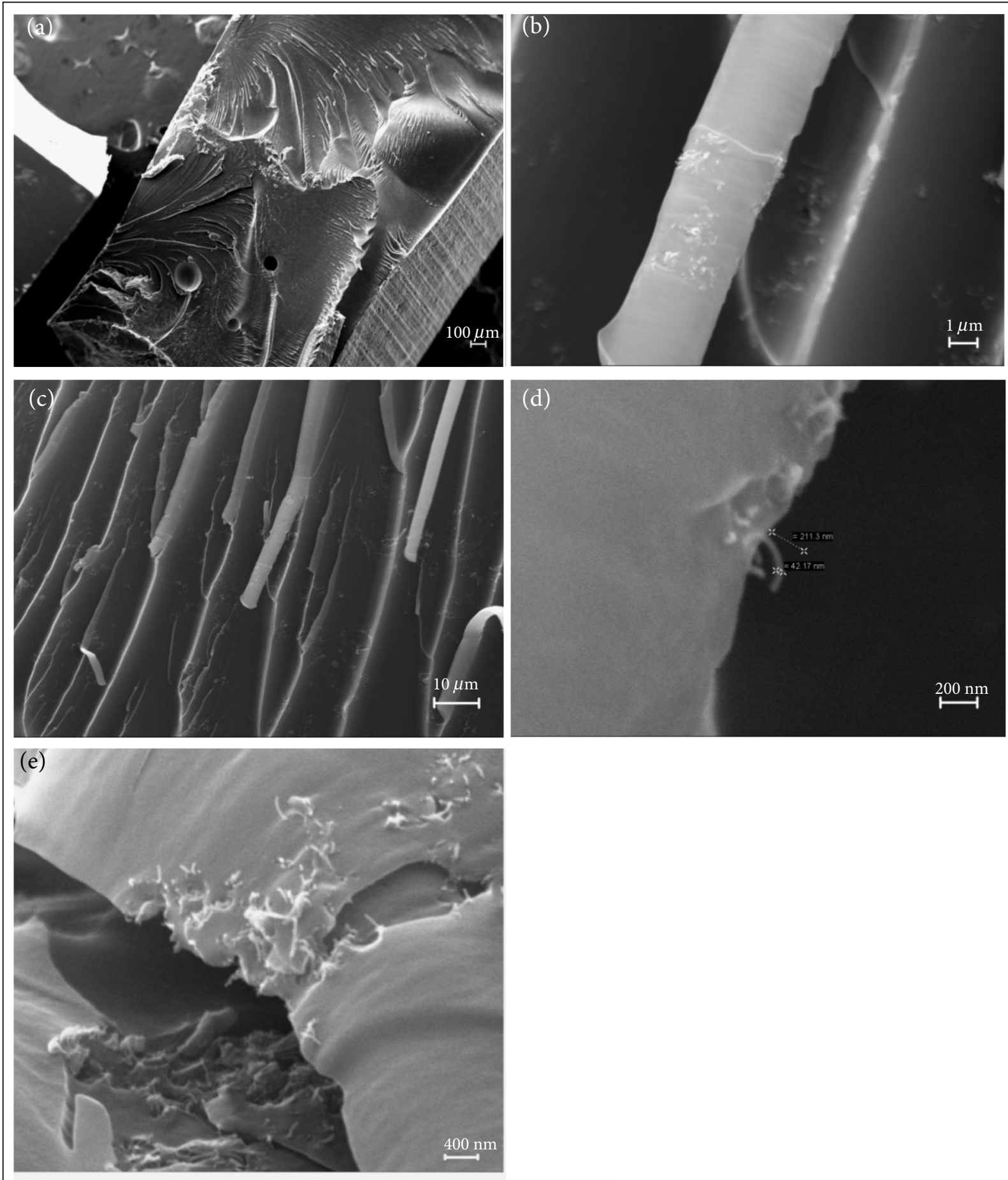

Fig. 1. SEM micrographs showing the fracture of epoxy resin NC filled with $1 \%$ wt. of CNT in different magnifications: (a) X100, (b) X3260, (c) X20000, (d) X132000, (e) X5200.

The NC density versus the filler content is shown in Fig. 2 where it is apparent that for low filler volume fractions (less than $1.0 \%$ wt.) there is a deviation between the results obtained from experimental measurements and those from the rule of mixtures. The nonlinear increase of the density at low volume fractions has also been reported by other researchers [18] and has been associated with the change in the free volume of epoxy resin. Equation (1) is an approximation that implies that the addition of the filler does not affect the free volume of the polymeric phase. It describes the size of space between the macromolecules that make up the so-called free volume. According to this theory the nanofillers do not completely occupy additional volume since part of them occupies the free volume of the epoxy network. 


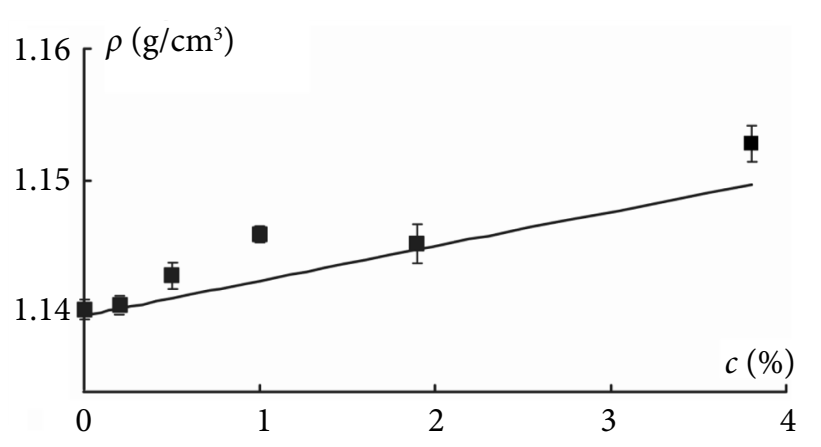

Fig. 2. Density of NC vs filler content (-) calculated by the rule of mixtures $(-)$.

In general, due to high density of CNTs, the density of manufactured samples increases with the increase in the filler content. When the concentration of CNTs reaches $3.8 \%$ wt., the density increases by $1.2 \%$ when compared to that of unfilled epoxy samples. The increase of density is associated with a relatively high density of CNT, but this dependence on the CNT content is not linear as expected. It can be described by CNT occupation of the free volume of epoxy resin and does not exert any influence on the density or other properties.

\subsection{Thermophysical properties}

The temperature range at which a sharp change in the thermal expansion rate of the NC specimens occurs can be determined from the dilatometric curves. It is well known that different structural changes can occur within NCs during the first cycle which can, in turn, lead to shrinkage and supplemental hardening of the specimens. In order to avoid these effects, the data of the second heating-cooling cycle were used in this study. Typical dilatometric curves for the epoxy matrix and the NC specimens with the maximal filler content are presented in Fig. 3 where it is shown that the neat epoxy resin is more deformable under temperature action. The $T_{\mathrm{g}}$ was determined from experimental heating curves as the crosspoint of two tangents which characterize CTE at temperature ranges before and after $T_{g}$ (Fig. 4(b)). From the dilatometry curves (Fig. 3 ) it is obvious that the $T_{\mathrm{g}}$ of $\mathrm{NC}$ with the maximal filler content is approximately by $17^{\circ} \mathrm{C}$ higher than that of the neat epoxy resin.

The data obtained from the dilatometric analysis (Fig.4) show that at the filler content $1.0 \%$ wt. $T_{\mathrm{g}}$ attains its maximum value with the latter being $23^{\circ} \mathrm{C}$ higher than that of the epoxy matrix (Fig. A). Further increase of the CNT loading causes a decrease in $T_{\sigma}$ which remains, however, higher than that of the unfilled epoxy sample. Similarly to other studies 110, 13, it has been found that the neat epoxy resin has higher CTE values compared to the loaded epoxy.

The results reported above can be explained when taking into account the formation of filler agglomerates within the material. Higher filler content results in a low degree of filler dispersion which in turn leads to a weak coupling between CNT and epoxy resin. Furthermore, agglomeration causes reduction of thermal stability and exerts influence on the viscoelastic behaviour of polymer material. This phenomenon has been

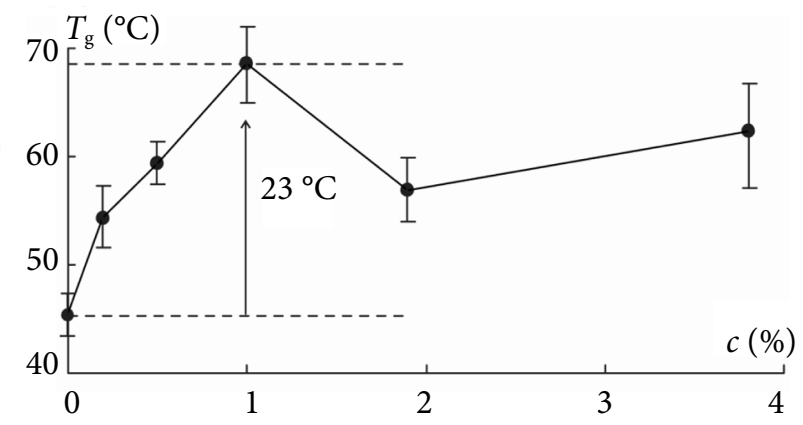

Fig. 4. Glass transition temperature vs the filler content in NC.

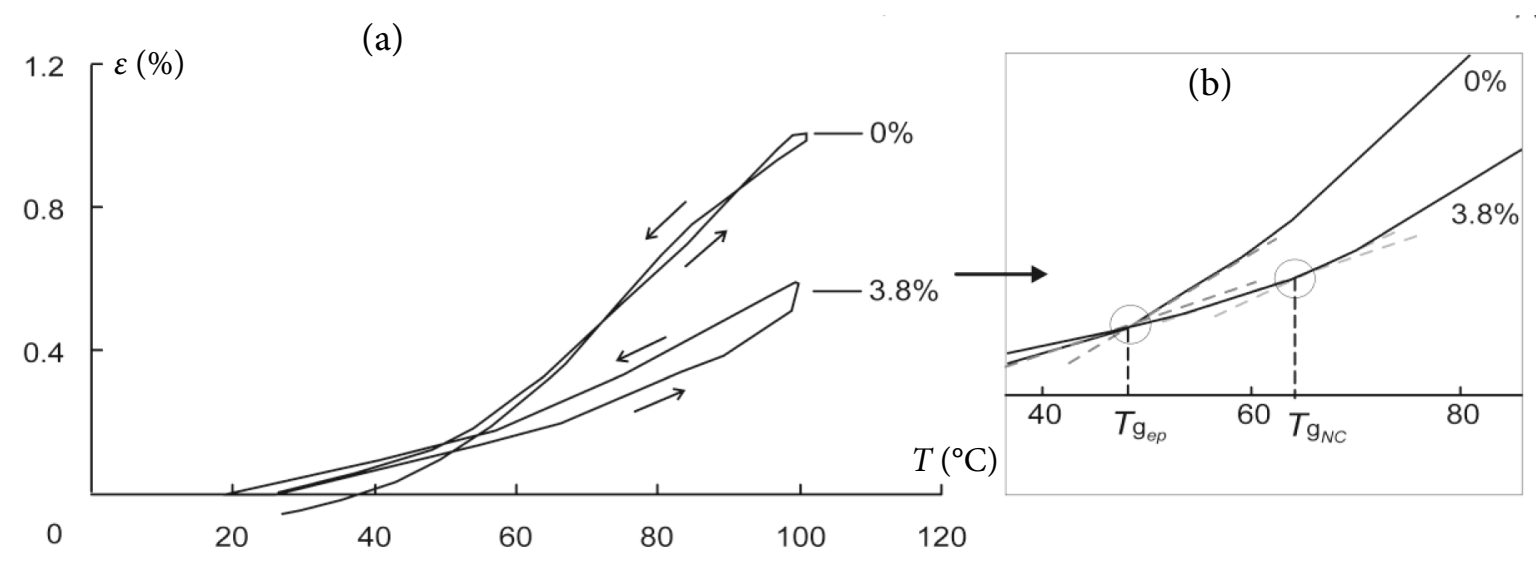

Fig. 3. Dilatometric curves for the heating-cooling cycle (a) and the $T_{\mathrm{g}}$ determination (b) of epoxy resin with 0 and $3.8 \%$ wt. CNT. 
explained in terms of the restriction of molecular motion [19]. At high loadings CNT occupies the free volume of epoxy resin which incites the decrease of $T_{\mathrm{g}}$. Agglomerated nanofillers and pores can be considered as defects in the material, therefore the glass transition temperature decreases with their increase. The changes in CTE (Fig. 5) can be considered negligible below the glass transition temperature $\left(T>T_{\mathrm{g}}\right)$. However, above the glass transition temperature $\left(T<T_{\mathrm{g}}\right)$, the CTE decreases up to $68 \%$ at the filler content $1.0 \% \mathrm{wt}$. compared to that of the neat epoxy resin (Fig. 5).

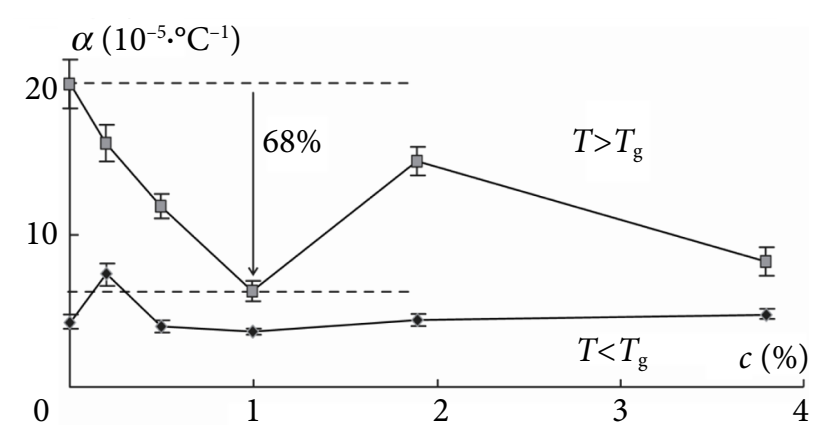

Fig. 5. The coefficient of thermal expansion vs the filler content in $\mathrm{NC}$ defined in different temperature ranges.

The values of $T_{\mathrm{g}}$, CTE and tensile strength show that the increasing of the filler content from 0 till $1 \%$ wt. show improvement of material properties, but after exceeding this optimal concentration properties get worse in comparison with the maximal improvements. The possible reason for the decrease of $T_{\mathrm{g}}$ and tensile strength, and the increase of CTE at higher CNT loadings can be a weak coupling between CNT and epoxy resin.

\subsection{Mechanical properties}

The mechanical properties of the NC (i. e. elastic modulus $E$, tensile strength $\sigma_{\text {max }}$ and strain at break $\varepsilon$ ) were determined from quasistatic tensile tests. The tensile stress-strain curves (Fig. 6) were used in order to estimate the mechanical characteristics of NC with different CNT content. The elastic modulus was obtained in the viscoelastic region, i. e. the region corresponding to strains from 0.05 to $0.25 \%$ (Fig. 6). The results indicate that the elastic modulus does not change distinctly and it is approximately constant, $3.14 \pm 0.02 \mathrm{GPa}$ for all filler contents. The effect of CNT on the modulus is minor, and this is primarily attributed to a relatively small filler content (in comparison to microfiller usual addition) and probable CNT agglomeration.

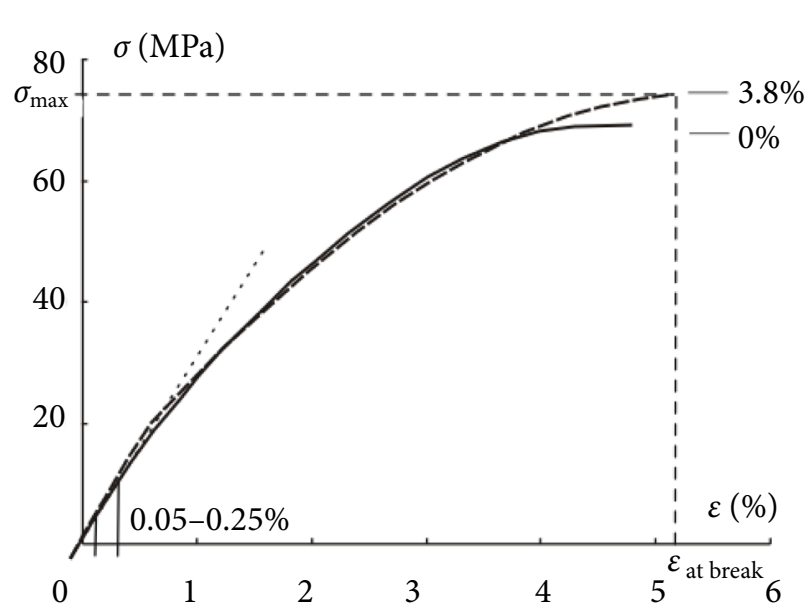

Fig. 6. Typical stress-strain curves of the epoxy resin specimen with 0 and $3.8 \%$ wt. of CNT (interval $0.05-$ $0.25 \%$ shows the elastic region on the curve).

In Fig. 月 the average values and standard deviations of $\sigma_{\max }$ and $\varepsilon_{\text {at break }}$ as obtained from testing five different specimens for each filler content are shown. However, it should be noted that for the CNT loading $1 \%$ wt. the average strain at break increases slightly by $0.8 \%$ and attains its maximum value. It is obvious that the polymer has the main impact on the elastic modulus and strain at break of NC and that CNTs do not exert visible influence.

In Fig. 7it is shown how the addition of CNTs influences the tensile strength $\left(\sigma_{\max }\right)$ of NCs. In particular, the tensile strength reaches its maximum for $1 \% \mathrm{wt}$. filler content with its value being $7 \%$ higher than that of the neat epoxy resin. A decrease of the tensile strength is observed with further addition of CNTs with the latter reaching a plateau with strength values higher than that of the neat epoxy resin. In general, the mechanical properties of the nanocomposite with the maximum (3.8\% wt.) filler content deteriorate when compared to those of the medium (1\% wt.) filled epoxy. This

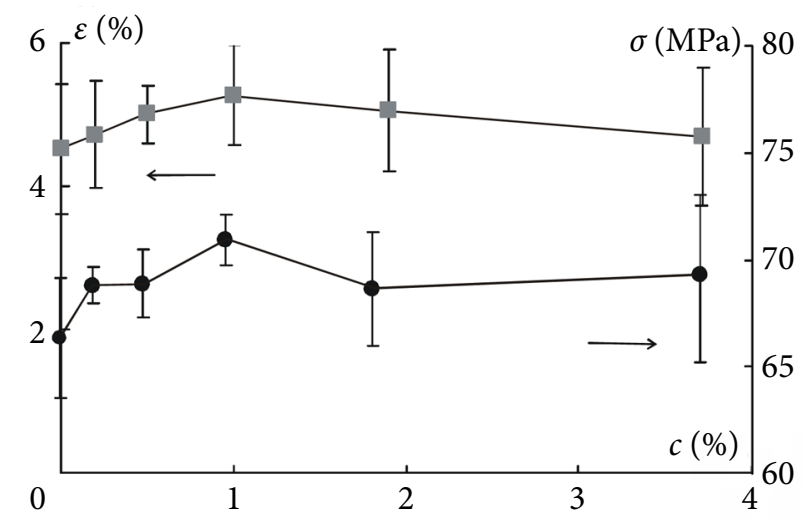

Fig. 7. Strain at break (--) and tensile strength (--) vs the filler content in NC. 
could be explained by higher nanofiller contents that cause deterioration of filler dispersion and thus reduce the strength of the material. Well-dispersed nanotubes should enhance the performance of epoxy resin; however, CNT agglomerations act as stress concentrators, decreasing their mechanical properties [1, 18]. It has been shown [5] that at higher CNT loadings the degree of improvement of mechanical properties is limited by the high viscosity which leads to the formation of agglomerates and defects. If the concentration of agglomerates increases and their sizes remain approximately constant, it could exert the influence on material like a microfiller, not a nanofiller. This statement is confirmed by SEM analysis. Agglomerates that are formed extensively with the increase of filler content and have different size can be associated as defects in nanocomposites.

The elastic modulus and strain at break remain practically constant. The practically constant elastic modulus and elongation at break in differently filled and unfilled epoxy resin are the result of very low filler volume fractions in this study.

\subsection{Correlation between thermophysical and mechanical properties}

Based on the results obtained for CNT/epoxy NC thermophysical and mechanical properties, some efforts are being made to correlate them (Fig. 8). As can be observed in Figs. 2, 3, 4, and 6, the experimental curves of $T_{g}$, CTE, strain at break and density have a similar nonlinear behaviour. The same CNT influence on the material structure and, as a result, on the NC mechanical and thermophysical properties was obtained.

The material density correlates with the glass transition temperature $T_{\mathrm{g}}$ (Fig. 8(a)) and they are increasing proportionally; this phenomenon is also mentioned by Montazeri et al. [19]. As the nanofiller content and density increase, the filler dispersion and the free volume within the material decrease. As a consequence, the agglomerates in the material are larger and more visible. When the dispersion is more homogeneous, the $T_{\mathrm{g}}$ increases and the movement of chains decreases, that improves the thermal stability. CTE characterizes deformation under the temperature action and this value is also interrelated to the mechanical properties of material. Consequently, CTE can be assumed proportional to the strain. The correlation between the changes of these two parameters is shown in Fig. 8(b).

The $T_{\mathrm{g}}$ and density, CTE and strain at break can be correlated using the Pearson's coefficient of correlation $r$ (or $r^{2}$ ), which determines the positive or negative correlation between the observed data and has values from -1 to 1 (the highest correlation). Using the Pearson's coefficient the same values of correlations were obtained for both cases (Fig. 8(a), (b)). Thus the correlation between $T_{\mathrm{g}}$ and density is positive, $r=0.64$, but between CTE and $\varepsilon_{\text {at break }}$ it is negative, $r=-0.64$. The correlation above 0.61 is defined as a strong correlation between the values.

The nonlinear dependence on the filler content can be mainly associated with the morphology and the structure of the polymer material obtained. The results indicate the efficiency of CNT reinforcement above and below the percolation threshold, where it can be observed that all the experimental data obtained have a nonlinear character on the filler content. The percolation threshold identifies the boundary filler content above which CNTs start to reduce their effective aspect ratio and, consequently, the efficiency of intercalations between the polymer and nanoparticles [14]. It can be observed in the figures (Figs. 2, 3,

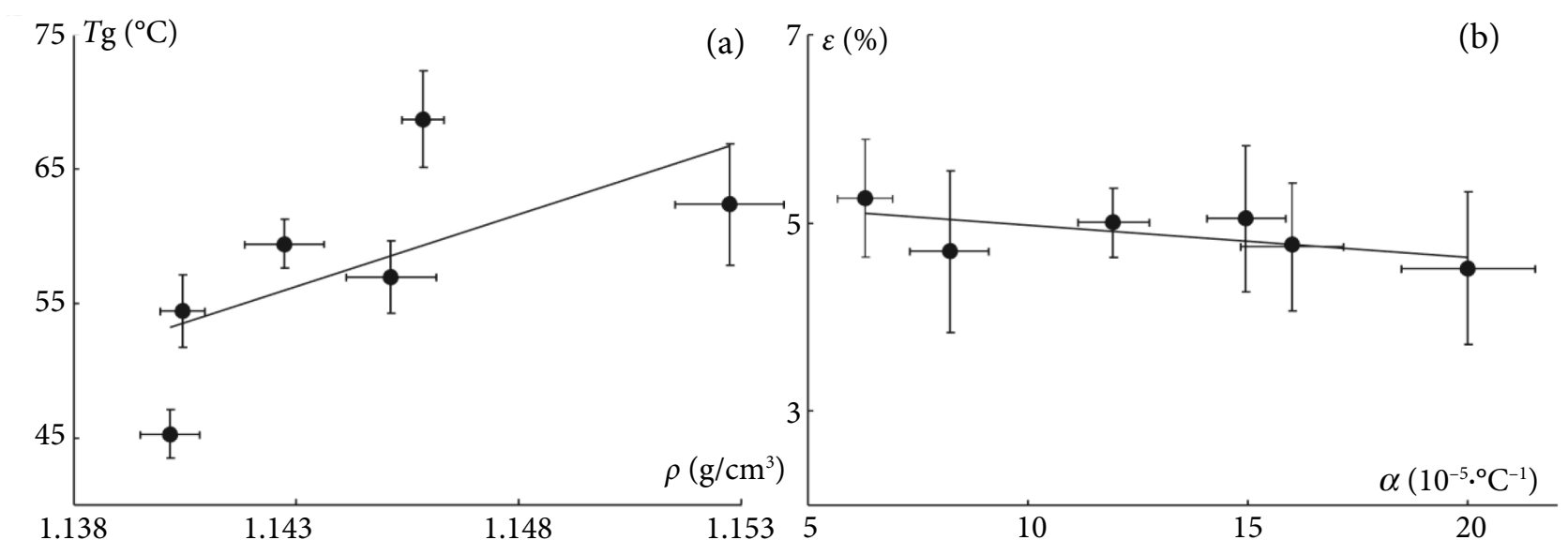

Fig. 8. Correlation between the glass transition temperature and density (a); between the coefficient of thermal expansion and strain at break (b) of NC. 
4. 6) shown in this work that at the filler content well above the percolation threshold (1.9\% wt.) properties get worse, but at 3.8\% wt. they again get higher. This phenomenon can be explained with consolidation of the polymer network and nanofiller because of high CNT loading that causes high viscosity. In high loadings the MWCNT aspect ratio also could be reduced during NC processing [14, 15. Thus because of cluster formation MWCNT added at high loadings could work as microfiller particles.

The obtained optimal filler content ( $1 \%$ wt.) was studied by SEM. The analysis was performed in order to study the structure and the filler dispersion of NC. The images at different magnifications show CNT distribution within the epoxy matrix. Figure 11 shows that the particles are separated and have a nanometre scale, but at higher magnification it can be observed that the length of a single MWCNT could start approximately from $0.1-0.5 \mu \mathrm{m}$ till several microns, but a typical diameter is about $40-60 \mathrm{~nm}$.

\section{Conclusions}

Based on the complex research experimental results, it is observed that the effect of introduction of CNT on the NC density, strain at break, tensile strength, CTE and $T_{\mathrm{g}}$ depending on the nanofiller content is nonlinear and shows the optimal filler content $1 \%$ wt.

The main conclusion is that addition of more CNT into epoxy resin does not mean improvement of the NC properties. Due to high viscosity the dispersion of CNT is not uniform at higher loading systems. If the filler content is exceeded over the percolation threshold, the composite becomes defective and its properties get worse. It happens due to agglomeration of small nanoparticles which results in a bad dispersion of the nanofiller that generally means that the NC has defects. The optimal percentage of the filler is associated with a sufficient quantity of the nanofiller that can improve properties of NC and have good dispersion and high aspect ratio of particles in the material.

An interesting fact is observed that after exceeding of $1 \%$ wt. CNT content the investigated properties get worse in comparison with maximal improvements. This phenomenon can be associated with the nanoparticle agglomeration because after exceeding the certain concentration (percolation threshold) the filler particles can work like micro- not nanofiller. As it is known, the microfiller also improves physical properties of the material but the improvements are minor than can be expected from the carbon nanofiller.

The obtained results show that the improvement of tensile strength and strain at break is quite insig- nificant, but it is necessary to notice that CNT addition in different content certainly does not deteriorate any characteristic of epoxy resin. The results show that CTE and $T_{\mathrm{g}}$ considerably increase at the defined optimal CNT content. Thus the range of possible application and multifunctionality of the material considerably increases.

\section{Acknowledgements}

The financial support through the European Social Fund Project No. 2013/0017/1DP/1.1.1.2.0/13/APIA/ VIAA/063 is greatly appreciated. The authors thank Konstantin Timchenko for his technical support during the specimen preparation, Dr. Jelena Faitelson for her help in the dilatometric analysis, and the Institute of Solid State Physics (University of Latvia) for the SEM images performed by Dr. Karlis Kundzins.

\section{References}

[1] J. Bicerano, Prediction of Polymer Properties (Marcel Dekker, New York, 2002) pp. 368-455, http://dx.doi.org/10.1002/pi.1643

[2] P. LeBaron, Z. Wang, and T.I. Pinnavaia, Polymerlayered silicate nanocomposites: an overview, Appl. Clay Sci. 15, 11-29 (1999), http://dx.doi. org/10.1016/S0169-1317(99)00017-4

[3] K. Aniskevich, O. Starkova, J. Jansons, and A. Aniskevich, Viscoelastic properties of a silicafilled styrene-butadiene rubber under uniaxial tension, Mech. Compos. Mater. 46, 375-386 (2010), http://dx.doi.org/10.1007/s11029-010-9154-x

[4] V. Singh, D. Joung, L. Zhai, S. Das, S.I. Khondaker, and S. Seal, Graphene based materials: Past, present and future, Progr. Mater. Sci. 56, 1178-1271 (2011), http://dx.doi.org/10.1016/j.pmatsci.2011.03.003

[5] M. Moniruzzaman and K.I. Winey, Polymer nanocomposites containing carbon nanotubes, Macromolecules 39, 5194-5205 (2006), http:// dx.doi.org/10.1021/ma060733p

[6] D.R.PaulandL.M.Robeson, Polymer nanotechnology: Nanocomposites, Polymer 49(15), 3187-3204 (2008), http://dx.doi.org/10.1016/j.polymer.2008.04.017

[7] I. Vera-Agullo, A. Gloria-Pereira, H. Varela-Rizo, J.L. Gonzales, and I. Martin-Gullon, Comparative study of the dispersion and functional properties of multiwall carbon nanotubes and helical-ribbon carbon nanofibers in polyester nanocomposites, Compos. Sci. Techn. 69, 1521-1532 (2009), http:// dx.doi.org/10.1016/j.compscitech.2008.11.032

[8] H.S. Khare and D.L. Burris, Quantitative method for measuring nanocomposite dispersion, Polymer 51, 719-729 (2010), http://dx.doi.org/10.1016/j. polymer.2009.12.031

[9] Z.K.Chen, J.P.Yang, Q.Q. Ni, S.Y. Fu., and Y.G. Huang, Reinforcement of epoxy resins with multi-walled 
carbon nanotubes for enhancing cryogenic mechanical properties, Polymer 50, 4753-4759 (2009), http:// dx.doi.org/10.1016/j.polymer.2009.08.001

[10] M. Abdalla, D. Dean, M. Theodore, J. Fielding, E. Nyairo, and G. Price, Magnetically processed carbon nanotube/epoxy nanocomposites: Morphology, thermal, and mechanical properties, Polymer 51, 1614-1620 (2010), http://dx.doi. org/10.1016/j.polymer.2009.05.059

[11] R.D. Maksimov, J. Bitenieks, E. Plume, J. Zicans, and R. Merijs Meri, The effect of introduction of carbon nanotubes on the physicomechanical properties of poly vinylacetate, Mech. Compos. Mater. 46(3), 237-242 (2010), http://dx.doi.org/10.1007/ s11029-010-9142-1

[12]L. Bokobza, Multiwall carbon nanotube elastomeric composites: a review, Polymer 48, 719-729 (2007), http://dx.doi.org/10.1016/j.polymer.2007.06.046

[13]A. Warrier, A. Godara, O. Rochez, L. Mezzo, F. Luizi, L. Gorbatikh, S.V. Lomov, A.V.V. Willem, and I. Verpoest, The effect of adding carbon nanotubes to glass/epoxy composites in the fibre sizing and/or the matrix, Compos. Appl. Sci. Manuf. 41, 532-538(2010), http://dx.doi.org/10.1016/j.compositesa.2010.01.001

[14]A. Martone, C. Formicola, M. Giordano, and M. Zarrelli, Reinforcement efficiency of multiwalled carbon nanotube/epoxy nano composites, Compos. Sci. Tech. 70, 1154-1160 (2010), http:// dx.doi.org/10.1016/j.compscitech.2010.03.001

[15] A. Martone, V. Faiella, V. Antonucci, M. Giordano, and M. Zarrelli, The effect of the aspect ratio of carbon nanotubes on their effective reinforcement modulus in an epoxy matrix, Compos. Sci. Tech. 71, 1117-1123 (2011), http://dx.doi.org/10.1016/j. compscitech.2011.04.002

[16]H.W. Wang, H.W. Zhou, R.D. Peng, and L. Mishnoevsky Jr., Nanoreinforced polymer composites:
3D FEM modeling with effective interface concept, Compos. Sci. Tech. 71, 980-988 (2011), http:// dx.doi.org/10.1016/j.compscitech.2011.03.003

[17] S.Y. Fu, X.Q. Feng, B. Lauke, and Y.W. Mai, Effect of particle size, particle/matrix interface adhesion and particle loading on mechanical properties of particulate composites, Compos. B Eng. 39, 933-961 (2008), http://dx.doi.org/10.1016/j.compositesb.2008.01.002

[18] S.G. Prolongo, M. Campo, M.R. Gude, R. ChaosMoran, and A. Urena, Thermo-physical characterization of epoxy resin reinforced by amino-functionalized carbon nanofibers, Compos. Sci. Tech. 69, 349-357 (2009), http://dx.doi.org/10.1016/j. compscitech.2008.10.018

[19] A. Montazeri, K. Pourshamsian, and M. Riazian, Viscoelastic properties and determination of free volume fraction of multi-walled carbon nanotube/epoxy composite using dynamic mechanical thermal analysis, Mater. Des. 36, 408-414 (2012), http://dx.doi.org/10.1016/j.matdes.2011.11.038

[20] V.K. Srivastava, Modeling and mechanical performance of carbon nanotube/epoxy resin composites, Mater. Des. 39, 432-436 (2012), http://dx.doi. org/10.1016/j.matdes.2012.02.039

[21]T. Glaskova, M. Zarrelli, A. Borisova, K. Timchenko, A. Aniskevich, and M. Giordano, Method of quantitative analysis of filler dispersion in composite systems with spherical inclusions, Compos. Sci. Tech. 71, 1543-1549 (2011), http://dx.doi.org/ 10.1016/j.compscitech.2011.06.009

[22] T. Glaskova, M. Zarrelli, A. Aniskevich, M. Giordano, L. Trinkler, and B. Berzina, Quantitative optical analysis of filler dispersion degree in MWCNT-epoxy nanocomposite, Compos. Sci. Tech. 72, 477-481 (2012), http://dx.doi.org/10.1016/j.compscitech.2011.11.029

[23] Technical data sheet of LH289 and H289 products, provided by Havel Composites company, 2009, http://www.havel-composites.cz

\title{
ŠILUMINĖS IR MECHANINĖS BISFENOLIO A EPOKSIDINĖS DERVOS, UŽPILDYTOS DAUGIASIENIAIS ANGLIES NANOVAMZDELIAIS, SAVYBĖS
}

\author{
A. Borisova, T. Glaskova-Kuzmina, A. Aniskevich
}

Latvijos universitetas, Ryga, Latvija 